\title{
MRI detection of endothelial cell inflammation using targeted superparamagnetic particles of iron oxide (SPIO)
}

\author{
Joyce M. S. Chan ${ }^{1,2,3^{*}}$, Maggie S. H. Cheung ${ }^{1}$, Richard G. J. Gibbs ${ }^{2}$ and Kishore K. Bhakoo ${ }^{3}$
}

\begin{abstract}
Background: There is currently no clinical imaging technique available to assess the degree of inflammation associated with atherosclerotic plaques. This study aims to develop targeted superparamagnetic particles of iron oxide (SPIO) as a magnetic resonance imaging (MRI) probe for detecting inflamed endothelial cells.

Methods: The in vitro study consists of the characterisation and detection of inflammatory markers on activated endothelial cells by immunocytochemistry and MRI using biotinylated anti-P-selectin and anti-VCAM-1 (vascular cell adhesion molecule 1) antibody and streptavidin conjugated SPIO.

Results: Established an in vitro cellular model of endothelial inflammation induced with TNF-a (tumor necrosis factor alpha). Inflammation of endothelial cells was confirmed with both immunocytochemistry and MRI. These results revealed both a temporal and dose dependent expression of the inflammatory markers, P-selectin and VCAM-1, on exposure to TNF-a.

Conclusion: This study has demonstrated the development of an in vitro model to characterise and detect inflamed endothelial cells by immunocytochemistry and MRI. This will allow the future development of contrast agents and protocols for imaging vascular inflammation in atherosclerosis. This work may form the basis for a translational study to provide clinicians with a novel tool for the in vivo assessment of atherosclerosis.
\end{abstract}

Keywords: Endothelial adhesion molecules, Atherosclerosis, MRI, Superparamagnetic particles of iron oxide, Vascular imaging, Inflammation imaging

\section{Background}

Atherosclerosis is a dynamic, progressive disease arising from the combination of endothelial dysfunction with a compensatory inflammatory response [1]. Inflammation is not only instrumental in the development of atheromatous plaques, but is also a key driver of plaque instability subsequently developing clinically significant symptoms such as stroke and myocardial infarction [1].

Current clinical techniques for imaging atherosclerotic disease include angiography, magnetic resonance angiography (MRA), computed tomography angiography (CTA) or ultrasound which principally gives an accurate

\footnotetext{
*Correspondence: joycechan@me.com

${ }^{1}$ Department of Surgery, Prince of Wales Hospital, The Chinese University of Hong Kong, Hong Kong SAR, People's Republic of China

Full list of author information is available at the end of the article
}

assessment of degree of luminal stenosis caused by atheroma. However, none of these techniques offer insight about the biological behaviour of atheromatous plaques-particularly degree of inflammation-which cause significant clinical events such as plaque instability and rupture [2].

MRI (magnetic resonance imaging) has advantages over other imaging modalities in clinical use, as it is noninvasive, does not involve ionising radiation and is able to provide high resolution images of the vessel wall at a sub-millimetre level [3]. In addition, recent development of advanced MR contrast agents that selectively target molecules involved in plaque inflammation, offering the promise of in vivo molecular MR imaging of atherosclerosis [4] and ex vivo MR imaging of vulnerable carotid plaque [5]. 
By exploiting specific 'inducible' molecular targets, or cellular events in diseases, molecular imaging uses targeted imaging agents to generate the image contrast [6]. One of the earliest events in atherosclerosis is the over-expression of adhesion molecules on the activated endothelium following exposure to inflammatory cytokines [7]. These pathophysiologically 'inducible' endothelial adhesion molecules, such as VCAM-1 (vascular cell adhesion molecule-1) and P-selectin, have the potential to serve as attractive biomarkers for imaging inflammation in atherosclerosis. VCAM-1 (CD106) is an immunoglobulin superfamily glycoprotein (100$110 \mathrm{kDa}$ ) expressed on activated endothelial cells, macrophages and smooth muscle cells [8]. It has a vital role in monocyte recruitment in early stages of atherosclerosis [9]. Its expression is upregulated by activated endothelium under inflammation, unlike resting endothelial cells [8]. The increased level of expression appears to be correlated with the extent of exposure to the atherosclerotic risk factors [8]. P-selectin (CD62P, GMP-140, PADGEM), a single-chain glycoprotein, is an adhesion molecule expressed on the surface of activated endothelial cells, which line the luminal surface of blood vessels, and on activated platelets [10]. It mediates initial leukocyte rolling, preceding leukocyte diapedesis into the atherosclerotic lesions [10, 11]. Similar to VCAM-1, P-selectin is rapidly mobilized to the surface of endothelial cells and platelets in response to stimuli [10]. These features render VCAM-1 and P-selectin an ideal biomarker for functional molecular imaging and targeted therapeutics in early atherosclerosis.

To achieve targeted molecular MR imaging, smarter contrast agents are required to identify the molecules of interest (i.e. endothelial adhesion molecules in atherosclerosis) with high specificity. Specificity can be achieved through conjugation of contrast agents with monoclonal antibodies, or their immunospecific fragments $F(a b)$ or peptides. Recent advances in this area include oxidized low-density lipoprotein (oxLDL)-targeted iron oxide nanoparticles [12] and scavenger receptor-AI-targeted iron oxide nanoparticles [13].

SPIO (superparamagnetic particles of iron oxide) nanoparticles are composed of an iron oxide core coated with a biocompatible polymer with size ranging from 50-300 $\mathrm{nm}$. Various iron-oxide nanoparticle preparations are under clinical trials and their safety profile has been increasingly recognised [14]. Iron-oxide particles have become the favoured contrast agent for a number of reasons. Firstly, they have a known biocompatibility profile with their degradation occurring through normal physiologic iron metabolism pathways [15]. By contrast, gadolinium chelates, the clinically used MRI contrast agent, has been reported to have potential severe long-term toxicity effects, including nephrogenic sclerosing fibrosis in patients with impaired renal function [16]. Secondly, iron-oxide particles have high sensitivity due to iron-oxide's inherent superparamagnetism. They distort magnetic fields, creating marked contrast effects far exceeding their physical size, thereby strongly enhancing the transverse relaxation times $\mathrm{T} 2$ and $\mathrm{T} 2 *$. Hence, they act as contrast agents for T2 sequence [15]. T2 technique is a relaxation time measurement contributing to the transverse decay of the MR signal that arise from natural interactions at the atomic and molecular levels within the tissue or substance of interest. T2* can be considered an "observed" T2, whereas T2 can be considered the "true" $\mathrm{T} 2$ of the tissue being imaged [17].

Iron-oxide nanoparticles have the potential to open up new avenues into molecular MR imaging, in both pre-clinical and clinical studies. Indirect quantitative methods utilising the non-specific uptake of iron-oxide particles by macrophages to identify plaque inflammation, have been reported [18]. The present study is an exploratory qualitative study aimed at visualising and characterising atherosclerosis using targeted SPIO as an MRI probe for detecting inflamed endothelial cells. It is hypothesized that highly specific antibody-conjugated SPIO would enable MRI of inflamed endothelial cells.

\section{Methods}

\section{Induction of inflammation on endothelial cells by TNF-a}

Mouse aortic endothelial cells (mAEC) (Innoprot, Spain) were cultured in an endothelial cell medium consisting of Dulbecco's Modified Eagle Medium containing $4500 \mathrm{mg} / \mathrm{L}$ glucose, L-glutamine and pyruvate, supplemented with $25 \mu \mathrm{g} / \mathrm{mL}$ of gentamicin, $2 \mathrm{mM}$ glutamine, $5 \%$ of fetal calf serum, $1 \mu \mathrm{g} / \mathrm{mL}$ of hydrocortisone, 10 units of heparin, $10 \mathrm{ng} / \mathrm{mL}$ of recombinant human epidermal growth factor (PeproTech Ltd, London, UK) and $3 \mathrm{ng} / \mathrm{mL}$ of recombinant human fibroblast growth factor (PeproTech Ltd, London, UK). mAEC were subsequently incubated with $0.1,1,10$ and $100 \mathrm{ng} / \mathrm{mL}$ recombinant mouse TNF- $\alpha$ (Sigma, MO, USA) for 4,24 and $48 \mathrm{~h}$ at $37{ }^{\circ} \mathrm{C}$ to induce endothelial VCAM-1 and P-selectin expression. mAECs without exposure to TNF- $\alpha$ served as controls.

\section{Detection of inflammatory markers on mAEC by immunocytochemistry}

mAECs on coverslips were harvested and fixed with 4\% paraformaldehyde (PFA) for $15 \mathrm{~min}$, permeabilized with $0.1 \%$ Triton X-100 for 5 min and blocked with 5\% bovine serum albumin (BSA) for $30 \mathrm{~min}$. Cells were then incubated with biotinylated primary antibody against VCAM-1 (Vector Laboratories, Burlingame, USA) and P-selectin (Vector Laboratories, Burlingame, USA) at 
room temperature for $1 \mathrm{~h}$, followed by streptavidin antibodies (Alexa Fluor ${ }^{\circledR} 594$ streptavidin, Thermofisher Scientific, Inc.) for $30 \mathrm{~min}$ at room temperature. After repeated wash with PBS, coverslips were mounted on a slide in antifade reagent with DAPI (ThermoFisher Scientific Inc.). An Olympus IX-83 inverted microscope fitted with a $60 \times, 1.4$ NA oil immersion objective (Olympus), and a monochrome CCD camera (Olympus) driven using CellSens (Olympus) were used. VCAM-1 and P-selectin fluorescence intensity per cell were quantified using software ImageJ $[19,20]$

\section{Corrected total cell fluorescence (CTCF)}

$=$ Integrated Density - (Area of selected cell $\times$ Mean fluorescence of background readings $)$ used as targeted 'contrast agents' for activated endothelial cells, thereby making these cells 'MR visible.' The cells were then incubated with the beads at $4{ }^{\circ} \mathrm{C}$ for $15 \mathrm{~min}$ and washed to remove unbound streptavidin microbeads afterwards. The cells were finally re-suspended in $150 \mu \mathrm{L}$ of PBS and $150 \mu \mathrm{L}$ of $2 \%$ agarose for cell phantom MRI. Inactivated cells (without TNF- $\alpha$ exposure) and activated cells incubated with biotinylated anti-mouse IgG (Vector Laboratories, Burlingame, USA) served as controls.

The cell suspensions in the tubes were embedded in $2 \%$ agarose block (Sigma ${ }^{\circledR}$, UK, Fig. 2). The cell phantom

\section{Detection of inflammatory markers on mAEC by MRI}

mAECs on the culture plates were used for the SPIO targeting to biotinylated antibodies conjugated on the cell surface as illustrated in Fig. 1. Firstly, the activated cells (1, 10 and $100 \mathrm{ng} / \mathrm{mL}$ TNF- $\alpha, 4 \mathrm{~h}$ ) were washed twice by centrifugation ( $5000 \mathrm{rpm}$ for $5 \mathrm{~min}$ ) and incubated at room temperature for $20 \mathrm{~min}$ with the biotinylated antiP-Selectin and anti-VCAM- 1 at a concentration of $10 \mu \mathrm{g} /$ $\mathrm{mL}$ diluted in $10 \%$ rabbit serum for labelling $10^{7}$ cells. Following incubation, the cells were washed twice to remove unbound biotinylated antibodies with $2 \mathrm{~mL}$ of labelling buffer composed of PBS $(1 \times)$, supplemented with $2 \mathrm{mM}$ EDTA, and centrifuged. The buffer was kept at $4{ }^{\circ} \mathrm{C}$ throughout the experiment to prevent capping of antibodies on the cell surface and non-specific cell labelling. The endothelial cell pellet was re-suspended in $90 \mu \mathrm{L}$ of labelling buffer per $10^{7}$ cells and $10 \mu \mathrm{L}$ of streptavidin microbeads (Miltenyi Biotec Ltd, Surrey, UK) per $10^{7}$ cells. These streptavidin microbeads are iron-oxide beads (SPIO of $50 \mathrm{~nm}$ diameter) conjugated to streptavidin and can be

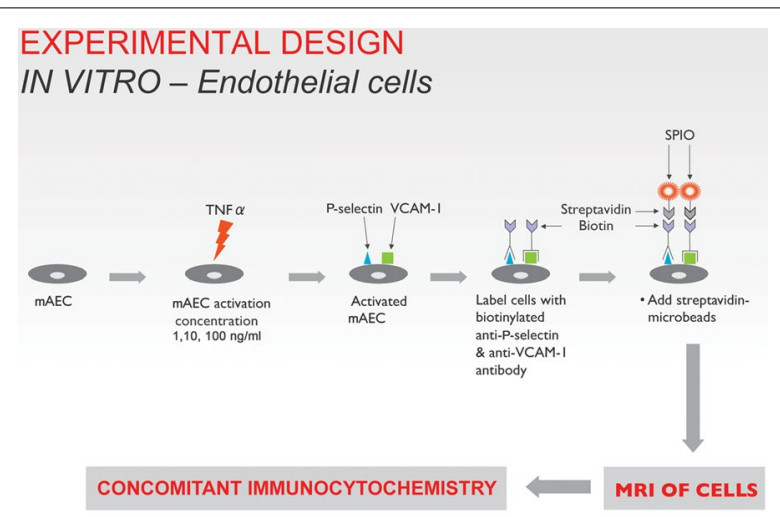

Fig. 1 Detection and characterisation of P-selectin and VCAM-1 on activated endothelial cells by antibody-conjugated SPIO
MRI was performed using a three tesla clinical whole body scanner (Achieva TX, Philips Healthcare, Best Netherlands). The samples were placed in a receive-only eight-channel SENSE wrist coil for optimal signal reception. A T2-weighted sequence (TR $2000 \mathrm{~ms}$; TE $120 \mathrm{~ms}$; number of slices 10; slice thickness $1 \mathrm{~mm}$; FOV $80 \mathrm{~mm}$; signal averages 30 ; matrix $266 \times 336$ ) was employed in the transverse plane to obtain sectional images of the samples. The MR images were analysed using ImageJ software. The signal to noise ratio for each sample was calculated to allow comparison amongst the samples.

\section{Statistical analysis}

The findings were analysed using the statistical software GraphPad Prism 5. The intensity of staining (CTCF) and signal to noise ratio was quantified as mean \pm SEM. Unpaired $t$ test was used to compare the means of CTCF between different concentrations of TNF- $\alpha$ in each time point. One way analysis of variance (ANOVA) test was used to perform multiple comparisons of mean CTCF at different concentrations of TNF- $\alpha$ and incubation periods. $P$ values less than 0.05 were taken as being statistically significant $\left({ }^{*} \mathrm{P}<0.05,{ }^{* * *} \mathrm{P}<0.01,{ }^{\text {***** }} \mathrm{P}<0.001\right)$.

\section{Results}

\section{Increased levels of P-selectin and VCAM-1 in activated mAEC}

P-selectin and VCAM-1 were only detected in activated mAEC as shown by the red fluorescence signal at various concentrations of TNF- $\alpha$ and incubation periods, whilst no expression was observed in the untreated control cells (Figs. 3a, 4a). The dose response of TNF- $\alpha$ in mAEC was similar as detected by P-selectin and VCAM-1. Higher TNF- $\alpha$ concentration gave higher expression levels of both inflammatory markers, although the expression level was more obvious in VCAM-1 compared to P-selectin (Figs. 3b, 4b). In addition, VCAM-1 expression increased with time, with maximal signal at $48 \mathrm{~h}$ (Fig. $4 \mathrm{~b}$ ), while 


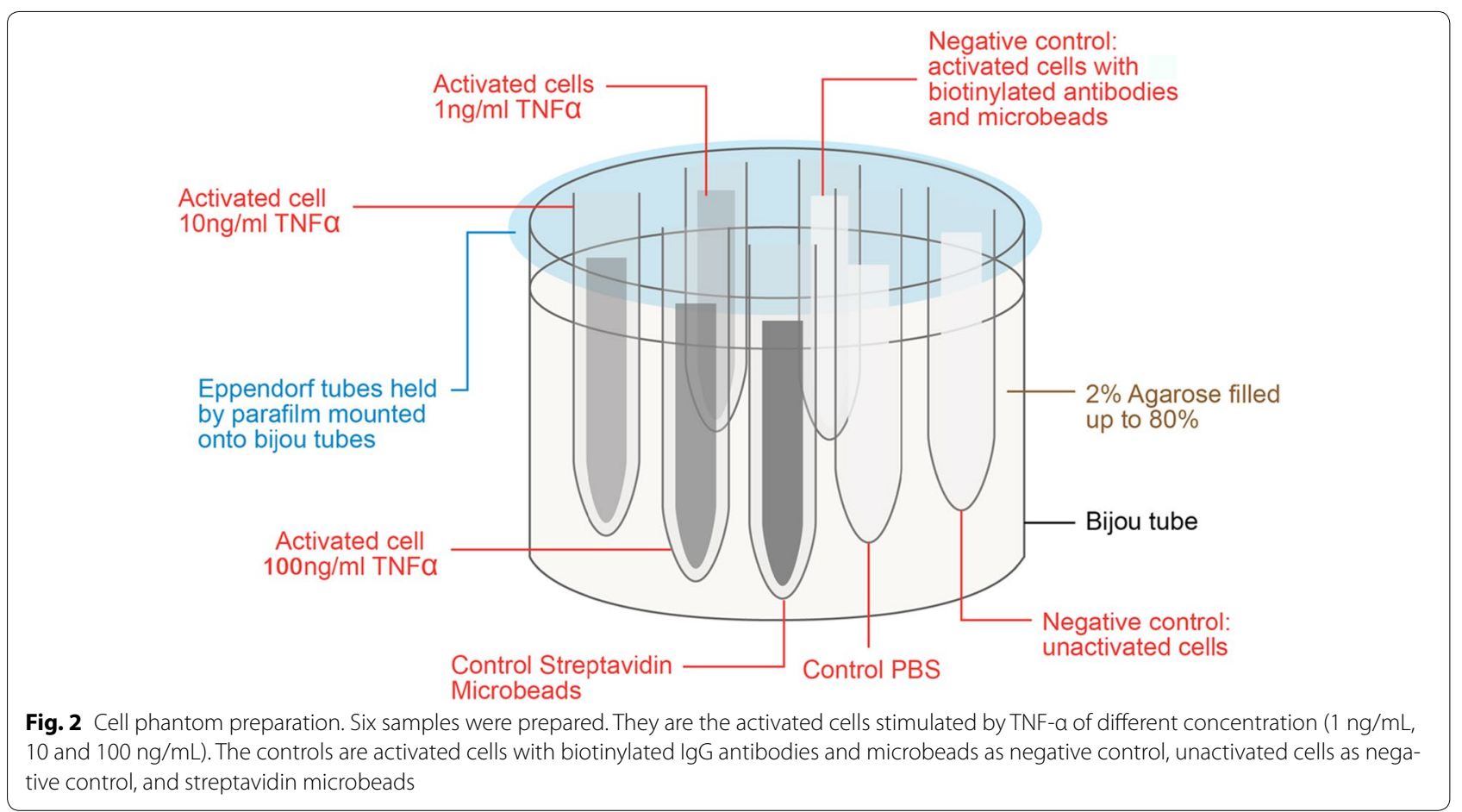

P-selectin level was maximal at $4 \mathrm{~h}$ post-TNF- $\alpha$ stimulation and then declined at 24 and $48 \mathrm{~h}$ (Fig. 3b).

\section{MRI signal concurs with the degree of inflammation in $\mathrm{MAEC}$}

The transaxial view of cell phantom MRI is illustrated in Fig. 5a. The streptavidin microbeads control were detected as signal void in T2 sequence by MRI and hence, appeared to be darkest. The activated mAEC stimulated by higher concentration of TNF- $\alpha$ were observed to produce greater signal void, and appeared darker on the MR image. The mAEC stimulated by $100 \mathrm{ng} / \mathrm{mL}$ TNF- $\alpha$ were observed to be the darkest amongst the three concentrations used, followed by $10 \mathrm{ng} / \mathrm{mL}$, and finally the least with $1 \mathrm{ng} / \mathrm{mL} \mathrm{TNF}-\alpha$. In contrast, the negative controls: (1) PBS (2) untreated mAEC, and (3) activated mAEC added with biotinylated IgG antibodies and microbeads were observed to produce minimal signal void, and appeared to be bright on the MR image.

In order to quantify these observations, the mean of the signal to noise ratio $(\mathrm{S} / \mathrm{N})$ in each sample in 5 consecutive MRI slices was measured. The results were illustrated in Fig. 5b. The $\mathrm{S} / \mathrm{N}$ in microbeads control was 0.243 , the lowest amongst all the samples. This was consistent with the observation that the microbeads control appeared to be the darkest amongst all samples. The activated cells stimulated by higher concentration of TNF- $\alpha$ produced a lower $\mathrm{S} / \mathrm{N}$.

\section{Discussion}

\section{Activated mAEC}

P-selectin is an adhesion molecule expressed on the luminal surface of vascular endothelial cells under inflammation [10]. It is not expressed by resting endothelial cells, but can be induced in vitro and in vivo following stimulation by pro-inflammatory mediators such as TNF- $\alpha$ or bacterial lipopolysaccharides [21, 22]. Previous studies have demonstrated P-selectin up-regulation in chronic inflammatory conditions such as rheumatoid arthritis [23] and inflammatory bowel disease [24]. By using P-selectin conjugated USPIO, Jacobin-Valat et al. demonstrated the expression of P-selectin on human activated platelets involved in the early stages of atherosclerosis [11]. Consistent with these studies, we confirmed that P-selectin expression was detected only on the activated mAECs, but not on the quiescent control mAEC (Fig. 3).

In our study, the P-selectin expression on activated mAEC was maximal at $4 \mathrm{~h}$ post-TNF- $\alpha$ stimulation, but declined after 24 and $48 \mathrm{~h}$. Similar transient expression of P-selectin in vitro has been reported on murine endothelial cells with maximal expression at $3 \mathrm{~h}$ after stimulation with TNF- $\alpha$ [21]. We have also demonstrated that the level of P-selectin expression was dose-dependent on exposure to TNF- $\alpha$, which is similar to E-selectin [25].

The role of VCAM-1 in the inflammatory initiation of atherosclerosis is well established in animal models [9]. In particular, VCAM-1 mediates firm adhesion, tethering, rolling of monocytes and facilitates their transendothelial 


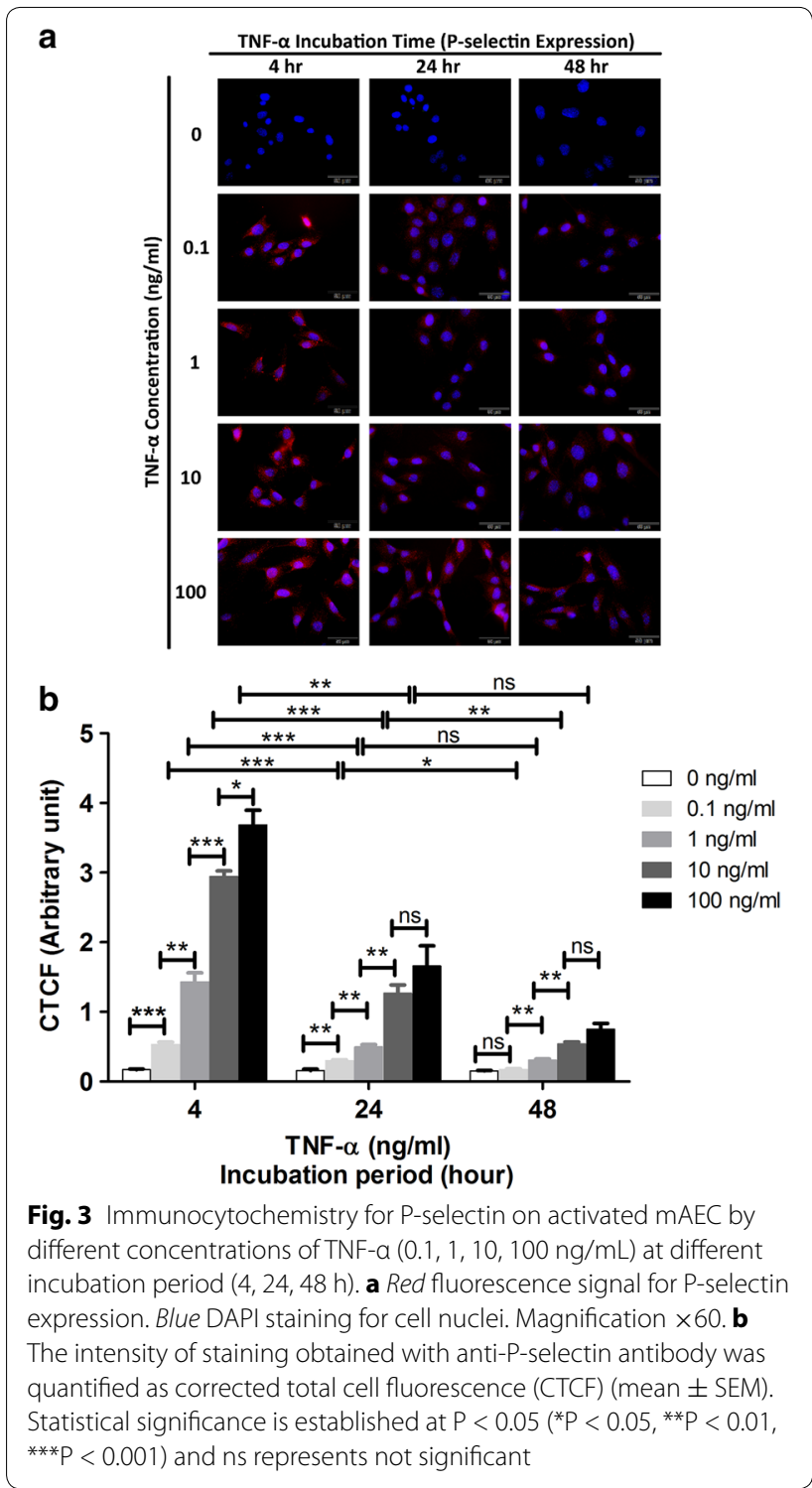

migration at the developing atheroma [26]. Its expression is upregulated on activated endothelium under inflammatory conditions, including atherosclerosis [7], transplant rejection [27] and cancer [28]. Davies et al. [29] found VCAM-1 expression in a majority of post-mortem human coronary atherosclerotic plaques. Furthermore, decreased VCAM-1 expression in experimental atherosclerosis appears after treatment with either HMG-CoA reductase inhibitors [30] or angiotensin receptor blockers [31]. A reduction in atherosclerotic lesion formation was found in genetically modified mice with impaired VCAM-1 function [26].

VCAM-1 expression is not constitutive of, but does appear on endothelial cell surface in atheroprone sites

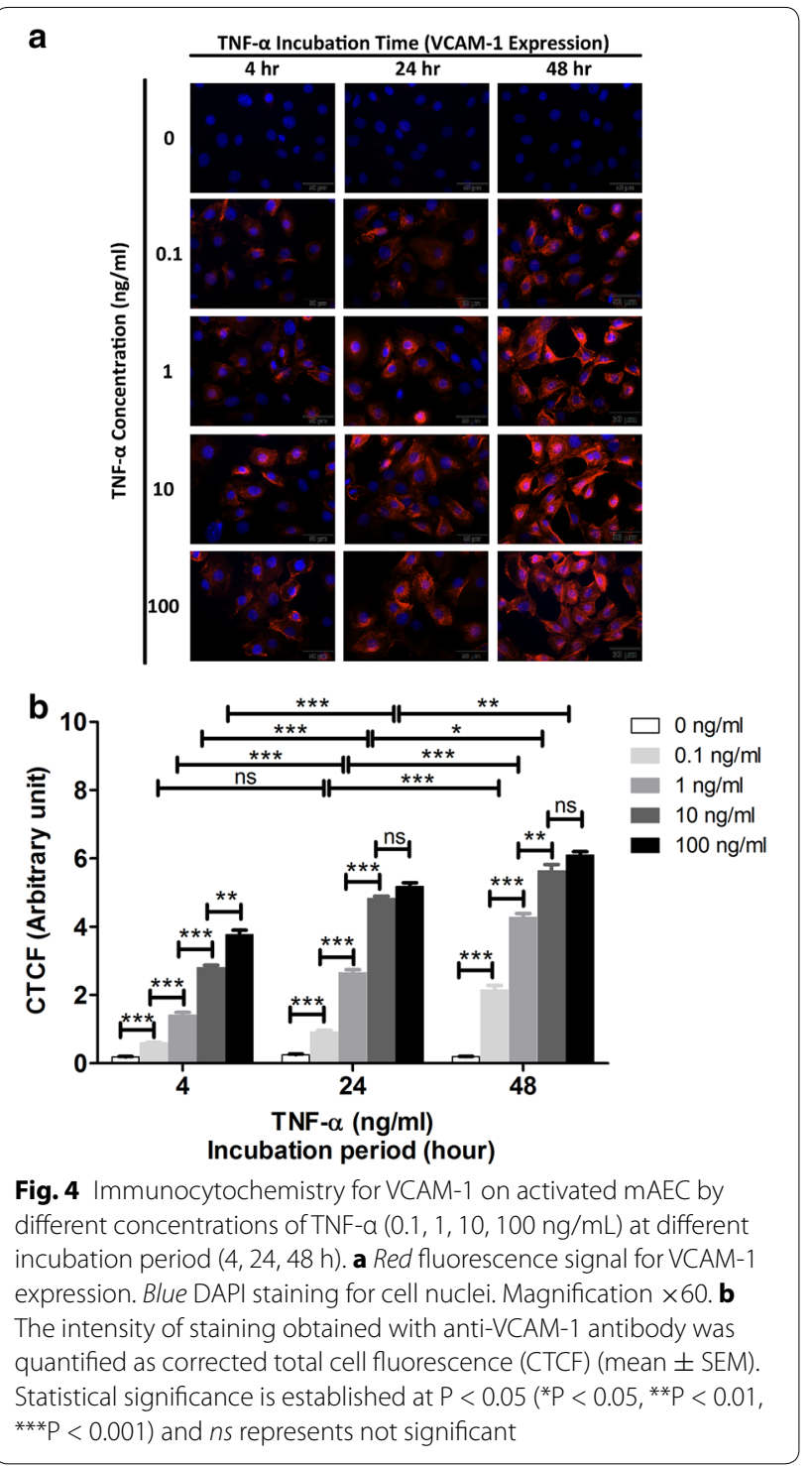

even before the onset of visible disease, with persistent expression in more advanced lesions [4]. Consistent with these previous studies, we confirmed that VCAM-1 expression was only detected on the activated mAEC (Fig. 4), but not on the silent control cells (Fig. 4).

McAteer et al. [4] demonstrated a dose dependent effect on the in vitro binding of anti-VCAM-1 microparticles of iron-oxide (MPIO) to TNF- $\alpha$-stimulated endothelial cells. We also observed similar dose-dependent increase in VCAM-1 expression, i.e. greater expression on the cells activated by higher concentration of TNF- $\alpha$.

Unlike P-selectin, previous studies reported that VCAM-1 had different kinetics of expression on human endothelial cells, with a later onset and a more prolonged duration of at least $72 \mathrm{~h}$ compared to that of P-selectin 
[32]. Our study revealed similar results: greater level of VCAM-1 expression was observed with longer incubation period. The VCAM-1 expression on activated mAEC revealed at $4 \mathrm{~h}$ after stimulation by TNF- $\alpha$, increased with longer incubation period and sustained a marked level of expression at $48 \mathrm{~h}$.

The strict temporal regulation of these inducible endothelial adhesion molecules, their critical functions in atherosclerosis and their immediate accessibility via the circulation provide valuable targets for functional molecular imaging and targeted therapeutics. This potentially provides a new biologically based imaging modality beyond anatomy to identify the 'at risk' group with unstable plaque disease, affording the opportunity for early stroke preventive treatment.

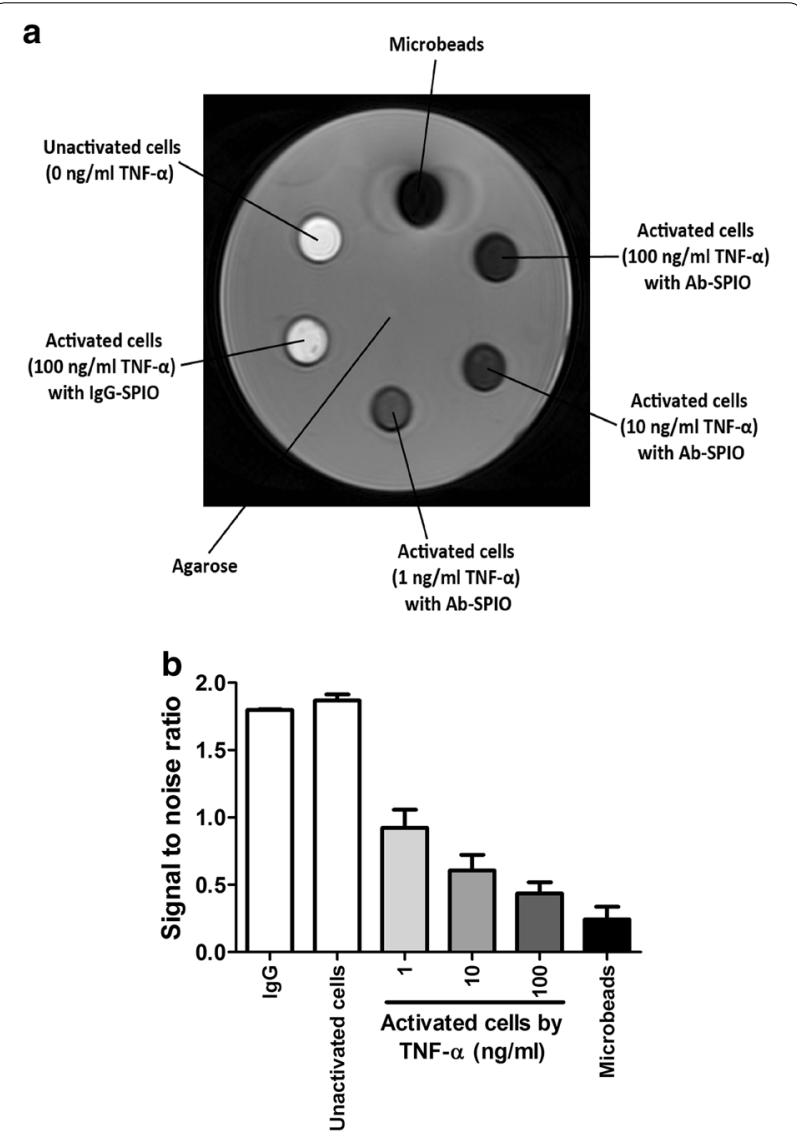

Fig. 5 The transaxial view of cell phantom MRI. a T2 sequence. In clockwise direction: the microbeads, activated mAEC stimulated by TNF- $a$ of different concentrations (100, 10 and $1 \mathrm{ng} / \mathrm{mL}$ ), activated mAEC added with biotinylated lgG antibodies and microbeads and unactivated $\mathrm{mAEC}$. $\mathbf{b}$ The $\mathrm{S} / \mathrm{N}$ in streptavidin microbeads, positive control, was the smallest amongst all the samples. The activated cells stimulated by higher concentration of TNF-a produced a lower S/N. By contrast, the negative controls: (1) unactivated mAEC, and (2) activated $\mathrm{mAEC}$ added with biotinylated IgG antibodies and microbeads produced high $\mathrm{S} / \mathrm{N}$

\section{In vitro studies-MRI of cells}

Figure 5 shows that the activated cells stimulated by higher concentration of TNF- $\alpha$ produced greater signal void and appeared darker in the MRI. The $\mathrm{S} / \mathrm{N}$ values were consistent with these observations of MRI of the cell phantoms. The higher concentration of TNF- $\alpha$ used to activate the $\mathrm{mAEC}$, the greater level of P-selectin and VCAM-1 expression on these cells. Therefore, greater amount of streptavidin microbeads were bound to the biotinylated anti-P-selectin and anti-VCAM-1 antibodies. Hence, greater signal loss was detected by MRI and lower $\mathrm{S} / \mathrm{N}$ in $\mathrm{mAEC}$ activated by higher concentration of TNF- $\alpha$. Therefore, we have successfully demonstrated an in vitro model to detect and characterise inflammation of endothelial cells by immunocytochemistry and MRI.

Similar in vitro studies with MRI of cell phantoms have been reported previously by McAteer et al. [4]. VCAM-1 conjugated microparticles of iron-oxide (MPIO) bound to TNF- $\alpha$ stimulated endothelial cells, but did not bind to unstimulated cells. The number of cell-bound VCAM-MPIO increased with increasing dose of TNF- $\alpha$. MRI of cell phantoms showed punctate dark signal areas (hypointensity) representing VCAM-1-MPIO binding to cells, which increased with higher dose of TNF- $\alpha$. Reynolds et al. demonstrated that E-selectin expression on activated vascular endothelium could be selectively and directly imaged non-invasively with in vivo MR by using anti-E-selectin antibody conjugated ultrasmall superparamagnetic iron oxide (USPIO) [15].

\section{Present challenges for in vivo molecular MRI}

The present challenge for in vivo molecular imaging is to deliver an effective contrast agent in sufficient quantity to the arterial wall in vivo. For a contrast agent to be effective, it must provide high sensitivity and relaxivity for detection by MRI. It also needs to be stable under physiological conditions. In addition, it has to be membrane permeable, non-cytotoxic, functionalisable and highly specific. There is a rapid growth in the use of iron-oxide particles for detecting vascular inflammation in vivo with MRI [15, 33-35]. Tang et al. [33] and Kawahara et al. [34] utilised the non-specific uptake of USPIO and SPIO by macrophages to identify plaque inflammation in humans. It has been speculated that this contrast medium is phagocytosed by macrophages and accumulates in the atherosclerotic lesions. This was an indirect method to visualise the plaque by macrophage infiltration. A relatively high dose of the agent is necessary to obtain good contrast effect and accumulation takes up to $24 \mathrm{~h}$. In contrast, our study is a pilot qualitative study where MRI with antibody-conjugated SPIO is 
used to assess the specific molecular events of vascular inflammation. Thus far, we have successfully developed an in vitro model to detect and characterise inflammation on the endothelial cells by both immunocytochemistry and MRI.

\section{Conclusion}

We have established a robust in vitro model of vascular inflammation using mAEC induced with TNF- $\alpha$. We have successfully detected and characterised the inflammation of endothelial cells by immunocytochemistry and MRI, which offers the potential for future translational studies to detect vascular inflammation in atherosclerosis. The results revealed a temporal expression in P-selectin and VCAM-1. In addition, the results suggested that the level of P-selectin and VCAM-1 expression was dose dependent on exposure to TNF- $\alpha$.

This proof-of-concept work may form the basis for further translational studies to provide clinicians with a novel tool for in vivo assessment of atherosclerosis. This will potentially fulfil the current gap to identify vulnerable patients, to better define cardiovascular risk and to guide therapy more rationally, thereby contributing to a personalised approach to the management of atherosclerotic disease in the future.

\begin{abstract}
Abbreviations
mAEC: mouse aortic endothelial cells; CTA: computed tomography angiography; DAPI: 4',6-diamidino-2-phenylindole; EDTA: ethylene diamine tetra acetic acid; FITC: fluorescein isothiocyanate; Ig: immunoglobulin; LL-1: interleukin-1; MPIO: microparticle of iron oxide; MRA: magnetic resonance angiography; MRI: magnetic resonance imaging; PBS: phosphate buffered saline; S/N: signal to noise ratio; $T 1$ : spin-lattice relaxation time; $T 2$ : spin-spin relaxation time; TNF-a: tumour necrosis factor-a; SPIO: superparamagnetic particles of iron oxide; VCAM-1: vascular cell adhesion molecule-1.
\end{abstract}

\section{Authors' contributions}

$J C$ and KB wrote the paper, designed and performed experiments; $M C$ performed experiments and data collection; KB and RG supervised the research design and the writing of the paper. All authors read and approved the final manuscript.

\section{Author details \\ ${ }^{1}$ Department of Surgery, Prince of Wales Hospital, The Chinese University of Hong Kong, Hong Kong SAR, People's Republic of China. ${ }^{2}$ Regional Vascular Unit, St Mary's Hospital, Imperial College Healthcare NHS Trust, Imperial Col- lege London, London, UK. ${ }^{3}$ Translational Molecular Imaging Group, Singapore Bioimaging Consortium, Agency for Science, Technology and Research (A*STAR), 11 Biopolis Way, Helios 138667, Singapore.}

\section{Acknowledgements}

This study was supported by The Direct Grant from The Chinese University of Hong Kong. We thank Professor James Y. W. Lau from Department of Surgery, The Chinese University of Hong Kong for his support in this study. We thank Dr. Wong Ka Tak and Mr. Mang Chun-Kit from Department of Radiology, Prince of Wales Hospital, Hong Kong for assistance with this study.

\section{Competing interests}

The authors declare that they have no competing interests.

Received: 1 December 2016 Accepted: 21 December 2016 Published online: 02 January 2017
References

1. Stoll G, Bendszus M (2006) Inflammation and atherosclerosis: novel insights into plaque formation and destabilization. Stroke 37:1923-1932

2. Virmani R, Burke AP, Kolodgie FD, Farb A (2003) Pathology of the thin-cap fibroatheroma: a type of vulnerable plaque. J Interv Cardiol 16:267-272

3. Millon A, Canet-Soulas E, Boussel L, Fayad Z, Douek P (2014) Animal models of atherosclerosis and magnetic resonance imaging for monitoring plaque progression. Vascular 22:221-237

4. McAteer MA, Schneider JE, Ali ZA, Warrick N, Bursill CA, von zur Muhlen C, Greaves DR, Neubauer S, Channon KM, Choudhury RP (2008) Magnetic resonance imaging of endothelial adhesion molecules in mouse atherosclerosis using dual-targeted microparticles of iron oxide. Arterioscler Thromb Vasc Biol 28:77-83

5. Chan JM, Monaco C, Wylezinska-Arridge M, Tremoleda JL, Gibbs RG (2014) Imaging of the vulnerable carotid plaque: biological targeting of inflammation in atherosclerosis using iron oxide particles and MRI. Eur J Vasc Endovasc Surg 47:462-469

6. Choudhury RP, Fuster V, Fayad ZA (2004) Molecular, cellular and functional imaging of atherothrombosis. Nat Rev Drug Disc 3:913-925

7. Libby P (2002) Inflammation in atherosclerosis. Nature 420:868-874

8. liyama K, Hajra L, liyama M, Li H, DiChiara M, Medoff BD, Cybulsky Ml (1999) Patterns of vascular cell adhesion molecule-1 and intercellular adhesion molecule-1 expression in rabbit and mouse atherosclerotic lesions and at sites predisposed to lesion formation. Circ Res 85:199-207

9. Ramos CL, Huo Y, Jung U, Ghosh S, Manka DR, Sarembock IJ, Ley K (1999) Direct demonstration of P-selectin- and VCAM-1-dependent mononuclear cell rolling in early atherosclerotic lesions of apolipoprotein $\mathrm{E}$ deficient mice. Circ Res 84:1237-1244

10. Frenette PS, Johnson RC, Hynes RO, Wagner DD (1995) Platelets roll on stimulated endothelium in vivo: an interaction mediated by endothelial P-selectin. Proc Natl Acad Sci USA 92:7450-7454

11. Jacobin-Valat MJ, Deramchia K, Mornet S, Hagemeyer CE, Bonetto $S$, Robert R, Biran M, Massot P, Miraux S, Sanchez S, Bouzier-Sore AK, Franconi JM, Duguet E, Clofent-Sanchez G (2011) MRI of inducible P-selectin expression in human activated platelets involved in the early stages of atherosclerosis. NMR Biomed 24:413-424

12. Wen S, Liu DF, Liu Z, Harris S, Yao YY, Ding Q, Nie F, Lu T, Chen HJ, An YL, Zang FC, Teng GJ (2012) OxLDL-targeted iron oxide nanoparticles for in vivo MRI detection of perivascular carotid collar induced atherosclerotic lesions in ApoE-deficient mice. J Lipid Res 53:829-838

13. Segers FM, den Adel B, Bot I, van der Graaf LM, van der Veer EP, Gonzalez W, Raynal I, de Winther M, Wodzig WK, Poelmann RE, van Berkel TJ, van der Weerd L, Biessen EA (2013) Scavenger receptor-Al-targeted iron oxide nanoparticles for in vivo MRI detection of atherosclerotic lesions. Arterioscler Thromb Vasc Biol 33:1812-1819

14. Taylor AM, Panting JR, Keegan J, Gatehouse PD, Amin D, Jhooti P, Yang GZ, McGill S, Burman ED, Francis JM, Firmin DN, Pennell DJ (1999) Safety and preliminary findings with the intravascular contrast agent NC100150 injection for MR coronary angiography. J Magn Reson Imaging 9:220-227

15. Reynolds PR, Larkman DJ, Haskard DO, Hajnal JV, Kennea NL, George AJ, Edwards AD (2006) Detection of Vascular Expression of E-selectin in vivo with MR Imaging. Radiology 241:469-476

16. Penfield JG, Reilly RF Jr (2007) What nephrologists need to know about gadolinium. Nat Clin Pract Nephrol 3:654-668

17. Haacke E, Brown R, Thompson M, Venkatesan R (1999) MRI physical principles and sequence design. Wiley-Liss, New York, NY

18. Hyafil F, Laissy JP, Mazighi M, Tchétché D, Louedec L, Adle-Biassette H, Chillon S, Henin D, Jacob MP, Letourneur D, Feldman LJ (2006) Ferumoxtran-10-enhanced MRI of the hypercholesterolemic rabbit aorta: relationship between signal loss and macrophage infiltration. Arterioscler Thromb Vasc Biol 26:176-181

19. Burgess A, Vigneron S, Brioudes E, Labbé J-C, Lorca T, Castro A (2010) Loss of human Greatwall results in $\mathrm{G} 2$ arrest and multiple mitotic defects due to deregulation of the cyclin B-Cdc2/PP2A balance. Proc Natl Acad Sci USA 107:12564-12569

20. Potapova TA, Sivakumar S, Flynn JN, Li R, Gorbsky GJ (2011) Mitotic progression becomes irreversible in prometaphase and collapses when Wee1 and Cdc25 are inhibited. Mol Biol Cell 22:1191-1206 
21. Weller A, Isenmann S, Vestweber D (1992) Cloning of the mouse endothelial selectins. Expression of both $\mathrm{E}$ - and P-selectin is inducible by tumor necrosis factor alpha. J Biol Chem 267:15176-15183

22. Liu Z, Zhang N, Shao B, Panicker SR, Fu J, McEver RP (2016) Replacing the promoter of the murine gene encoding P-selectin with the human promoter confers human-like basal and inducible expression in mice. J Biol Chem 291:1441-1447

23. Habets KL, Trouw LA, Levarht EW, Korporaal SJ, Habets PA, de Groot P, Huizinga TW, Toes RE (2015) Anti-citrullinated protein antibodies contribute to platelet activation in rheumatoid arthritis. Arthritis Res Ther 17:209

24. Hoffmann U, Pink M, Lauer U, Heimesaat MM, Winsauer C, Kruglov A, Schlawe K, Leichsenring C, Liesenfeld O, Hamann A, Syrbe U (2013) Regulation and migratory role of P-selectin ligands during intestinal inflammation. PLoS ONE 8:e62055

25. Kilgore KS, Shen JP, Miller BF, Ward PA, Warren JS (1995) Enhancement by the complement membrane attack complex of tumor necrosis factoralpha-induced endothelial cell expression of E-selectin and ICAM-1.J Immunol 155:1434-1441

26. Cybulsky MI, liyama K, Li H, Zhu S, Chen M, liyama M, Davis V, GutierrezRamos JC, Connelly PW, Milstone DS (2001) A major role for VCAM-1, but not ICAM-1, in early atherosclerosis. J Clin Invest 107:1255-1262

27. Rothman A, Mann D, Behling CA, McGraw M, Seslar S, Shiu P, Zhang L, Kriett JM (2003) Increased expression of endoarterial vascular cell adhesion molecule-1 mRNA in an experimental model of lung transplant rejection: diagnosis by pulmonary arterial biopsy. Transplantation 75:960-965

28. Alexiou D, Karayiannakis AJ, Syrigos KN, Zbar A, Kremmyda A, Bramis I, Tsigris C (2001) Serum levels of E-selectin, ICAM-1 and VCAM-1 in colorectal cancer patients: correlations with clinicopathological features, patient survival and tumour surgery. Eur J Cancer 37:2392-2397
29. Davies MJ, Gordon JL, Gearing AJ, Pigott R, Woolf N, Katz D, Kyriakopoulos A (1993) The expression of the adhesion molecules ICAM-1, VCAM-1, PECAM, and E-selectin in human atherosclerosis. J Pathol 171:223-229

30. Sukhova GK, Williams JK, Libby P (2002) Statins reduce inflammation in atheroma of nonhuman primates independent of effects on serum cholesterol. Arterioscler Thromb Vasc Biol 22:1452-1458

31. Candido R, Allen TJ, Lassila M, Cao Z, Thallas V, Cooper ME, JandeleitDahm KA (2004) Irbesartan but not amLodipine suppresses diabetes associated atherosclerosis. Circulation 109:1536-1542

32. Pober JS, Gimbrone MA Jr, Lapierre LA, Mendrick DL, Fiers W, Rothlein R, Springer TA (1986) Overlapping patterns of activation of human endothelial cells by interleukin 1, tumor necrosis factor, and immune interferon. J Immunol 137:1893-1896

33. Tang TY, Howarth SP, Miller SR, Graves MJ, Patterson AJ, U-King-Im JM, Li ZY, Walsh SR, Brown AP, Kirkpatrick PJ, Warburton EA, Hayes PD, Varty K, Boyle JR, Gaunt ME, Zalewski A, Gillard JH (2009) The ATHEROMA (atorvastatin therapy: effects on reduction of macrophage activity) study. Evaluation using ultrasmall superparamagnetic iron oxide-enhanced magnetic resonance imaging in carotid disease. J Am Coll Cardiol 53:2039-2050

34. Kawahara I, Nakamoto M, Kitagawa N, Tsutsumi K, Nagata I, Morikawa M, Hayashi T (2008) Potential of magnetic resonance plaque imaging using superparamagnetic particles of iron oxide for the detection of carotid plaque. Neurol Med Chir (Tokyo) 48:157-161

35. McAteer MA, Mankia K, Ruparelia N, Jefferson A, Nugent HB, Stork LA, Hagen R, Channon KM, Schneider JE, Choudhury RP (2012) A leukocytemimetic magnetic resonance imaging contrast agent homes rapidly to activated endothelium and tracks with atherosclerotic lesion macrophage content. Arterioscler Thromb Vasc Biol 32:1427-1435

\section{Submit your manuscript to a SpringerOpen ${ }^{\circ}$ journal and benefit from:}

- Convenient online submission

- Rigorous peer review

- Immediate publication on acceptance

- Open access: articles freely available online

- High visibility within the field

- Retaining the copyright to your article

Submit your next manuscript at springeropen.com 